\title{
Degassing at Sabancaya volcano measured by UV cameras and the NOVAC network
}

\author{
Tehnuka Ilanko ${ }^{\star \alpha}$, Thomas D. Pering ${ }^{\alpha}$, Thomas C. Wilkes ${ }^{\alpha}$, Fredy E. Apaza Choquehuayta ${ }^{\beta}$, \\ Christoph Kern $\gamma$, Alejandro Díaz Moreno ${ }^{\delta}$, Silvio De Angelis $\delta$, Susana Layana ${ }^{\varepsilon, \zeta}$, , Felipe \\ Rojas $^{\eta}$, Felipe Aguilera ${ }^{\epsilon, \eta}$, Freddy Vasconez ${ }^{\vartheta}$, Andrew J. S. McGonigle ${ }^{\alpha, \iota, \kappa}$ \\ ${ }^{\alpha}$ Department of Geography, University of Sheffield, UK \\ ${ }^{\star}$ Full list of affiliations given in Affiliations section.
}

\begin{abstract}
We used low-cost Raspberry Pi ultraviolet (UV) cameras to measure sulphur dioxide $\left(\mathrm{SO}_{2}\right)$ fluxes from Sabancaya volcano, Peru, during eruptive activity on 27 April 2018. Light dilution corrections were made by operating instruments at two distances simultaneously. Estimated $\mathrm{SO}_{2}$ fluxes of $27.1 \mathrm{~kg} \mathrm{~s}^{-1}$ are higher than previously reported, likely due to the current eruptive episode (ongoing since November 2016). Each eruptive event included frequent (2-3 per minute), ash-rich emissions, forming gas pulses with masses of 3.0-8.2 tonnes $\mathrm{SO}_{2}$. Sustained degassing and lack of overpressure suggest open-vent activity. Mean fluxes are consistent with those measured by a permanent NOVAC station $\left(25.9 \mathrm{~kg} \mathrm{~s}^{-1}\right)$ located under the plume, with remaining differences likely due to windspeed estimates and sampling rate. Our work highlights the importance of accurate light dilution and windspeed modelling in $\mathrm{SO}_{2}$ retrievals and suggests that co-location of UV cameras with permanent scanning spectrometers may be valuable in providing accurate windspeeds.
\end{abstract}

\section{RESUMEN}

Utilizamos cámaras ultravioletas (UV) Raspberry Pi para medir los flujos de dióxido de azufre $\left(\mathrm{SO}_{2}\right)$ en el volcán Sabancaya, Perú, durante la actividad del 27 abril 2018. La corrección por dilución de luz se realizó midiendo simultáneamente en dos sitios a diferentes distancias. Los flujos promedio $\left(27.1 \mathrm{~kg} \mathrm{~s}^{-1}\right)$ son superiores a los reportados previamente, probablemente debido al actual episodio explosivo. Cada evento tuvo frecuentes emanaciones ricas en ceniza y gas, emitiendo 3.0-8.2 toneladas de $\mathrm{SO}_{2}$. La desgasificación sostenida, sin sobrepresión, indica una chimenea abierta. Estos flujos son similares a los medidos en una estación permanente de NOVAC $\left(25.9 \mathrm{~kg} \mathrm{~s}^{-1}\right)$ debajo de la pluma. La diferencia restante es por velocidad del viento estimada y la frecuencia de la muestreo. Nuestro trabajo muestra la importancia de modelar con precisión la dilución de luz y velocidad del viento, y que co-instalar cámaras UV y espectrómetros permanentes podrían dar velocidades del viento más exactos.

Keywords: Sulphur dioxide; PiCam; UV camera; NOVAC; DOAS; Sabancaya

\section{INTRODUCTION}

Small, low cost, ultraviolet (UV) cameras with low power requirements [Wilkes et al. 2016; Wilkes et al. 2017] have facilitated quantification of sulphur dioxide $\left(\mathrm{SO}_{2}\right)$ in volcanic plumes, while also providing timeseries images that can be used for tracking plume features and explosions [e.g. Peters et al. 2015]. Higher temporal resolutions can be achieved with a UV camera than with differential optical absorption spectroscopy (DOAS) based methods that require scanning through the plume [e.g. Galle et al. 2003; McGonigle et al. 2009; McGonigle et al. 2017]. Windspeeds for calculating $\mathrm{SO}_{2}$ fluxes can also be obtained directly from UV im-

${ }^{*}$ Corresponding author: tehnuka@volcanofiles.com age sequences [e.g. Gliß et al. 2018; Peters and Oppenheimer 2018], whereas windspeeds for DOAS flux calculations often require the use of multiple scanners and cross-correlation [McGonigle et al. 2009; Galle et al. 2010], independent windspeeds from in situ measurements [e.g. Prata 2013], or forecast models [Lübcke et al. 2013]. Long-term ground-based monitoring of volcanic $\mathrm{SO}_{2}$ emissions, however, with rare exceptions (Burton et al. [2015] at Stromboli; Kern et al. [2018] at Kīlauea Volcano; D'Aleo et al. [2016] at Mt Etna), uses scanning DOAS. The development of low-cost UV camera alternatives is recent, and despite the advantages of higher temporal and spatial resolutions, challenges remain with image-based measurements. For example, regular calibration is needed with changing light con- 
ditions, using $\mathrm{SO}_{2}$-filled gas cells or a co-aligned DOAS instrument, and clouds in front of the plume can prevent accurate $\mathrm{SO}_{2}$ retrievals [Lübcke et al. 2013].

The Network for Observation of Volcanic and Atmospheric Change, NOVAC [Galle et al. 2010], operates a network of ground-based permanent scanning DOAS spectrometers for automated $\mathrm{SO}_{2}$ flux measurements that currently monitors 42 volcanoes (https://novaccommunity.org/volcanoes, accessed on 10 June 2019). The system includes software providing automated calculations of windspeed and fluxes. Ideally, spectrometers scan perpendicular to the wind direction with different viewing angles to measure $\mathrm{SO}_{2}$ slant column amounts [Galle et al. 2010]. The primary source of error under favourable meteorological conditions is in windspeed estimates, which use either the lag between column amounts for two scanners or an external windspeed model. However, plume height estimates, light dilution and scattering may also contribute significantly to errors [Galle et al. 2010], with the magnitude of errors being dependent on time- and locationspecific parameters. In addition, a lack of plume-free sky will result in reference spectra contaminated by $\mathrm{SO}_{2}$, causing fluxes to be underestimated [Lübcke et al. 2016]. While data from the network are valuable for permanent monitoring of $\mathrm{SO}_{2}$ emissions and comparison of degassing at different sites, it is also useful to compare these with data collected by other methods. Here, therefore, we demonstrate the use of low-cost UV cameras [PiCams: Wilkes et al. 2016; Wilkes et al. 2017] in a comparison with $\mathrm{SO}_{2}$ fluxes collected by NOVAC permanent DOAS scanning stations at Sabancaya volcano, Peru, in April 2018.

\subsection{Activity at Sabancaya volcano}

Sabancaya is an active, persistently degassing stratovolcano in the south of the Peruvian volcanic arc (Figure 1). Episodes of heightened activity over the past three decades have been explosive [e.g. Samaniego et al. 2016] and the latest such episode, which started in 2016, includes regular and sustained ash- rich explosions producing plumes averaging $2-4 \mathrm{~km}$ in height [OVI-INGEMMET \& IGP 2018]. These frequent explosions ( 20-30 explosions/day during the week of 23 April 2018), are associated with increases in $\mathrm{SO}_{2}$ emissions from the summit area. producing plumes averaging $2-4 \mathrm{~km}$ in height [OVI-INGEMMET \& IGP 2018]. However, of the 26 explosions identified by long period earthquakes and tremors on 27 April 2018, none occurred during the measurement period, with several hours' interval between one explosion at 13:41 UTC and the next at 16:32 UTC.

Mean $\mathrm{SO}_{2}$ fluxes from Sabancaya for the period 2005-2015 were reported from the Ozone Monitoring Instrument (OMI) satellite retrievals by Carn et al. [2017] to be $87 \mathrm{td}^{-1}$ with 1 s.d. of $158 \mathrm{td}^{-1}$. Their annual data show an increase in $\mathrm{SO}_{2}$ fluxes over the past decade. Using UV cameras and scanning DOAS, Moussallam et al. [2017] found higher $\mathrm{SO}_{2}$ fluxes from 1.5 hours of data in November 2015, with a notable difference between the lower DOAS and higher UV camera fluxes (Table 1), which they attribute to differences in temporal resolution and retrieval procedures. Finally, Kern et al. [2017] calculated an average of $890 \mathrm{td}^{-1}$ from two hours of DOAS data in May 2016, six months before the start of the current eruptive episode. The range of these reported fluxes likely reflect differences in measurement and retrieval techniques as well as changes in activity. Leading up to the start of the eruption in November 2016, new fumarolic activity was observed in the summit area, and an increase in daily $\mathrm{SO}_{2}$ fluxes was identified by the Observatorio Volcanológico del INGEMMET using the scanning DOAS stations in the NOVAC network [Ramos Palomino et al. 2016]. Further details on the onset of this eruptive episode are available in reports by the Observatorio Volcanológico del INGEMMET [Ramos Palomino et al. 2016] and the Global Volcanism Program. Data reported here were collected by PiCams deployed on 27 April 2018 during a NOVAC workshop [Kern et al. 2018], and from NOVAC scans over the same period.

We provide here the first comparison of contemporaneous UV camera- and NOVAC-derived volcanic $\mathrm{SO}_{2}$ fluxes, and use this example to explore sources of uncertainty that pose ongoing challenges to $\mathrm{SO}_{2}$ flux estimates, due to the difficulty in quantifying the associated errors. We also consider eruption mechanisms that could explain the qualitative observations of activity at Sabancaya during these measurements.

\section{Methods}

The following sections provide details of data collection from UV cameras (Subsection 2.1) and the NOVAC scanning network (Subsection 2.2). Infrasound data (Subsection 2.3) were also available for this time period from a permanent station $\sim 2.7 \mathrm{~km} \mathrm{SW}$ of the active vent.

\subsection{PiCams, field methods and analyses}

To view the plume, which was moving to the northeast, three Raspberry Pi (PiCam)-based UV camera units [Wilkes et al. 2016; Wilkes et al. 2017] were set up about $10.29 \mathrm{~km}$ from the summit crater of Sabancaya (Figure 1, 'Far camera site'). Data from two of these cameras, Cameras A and B, are reported here. A fourth unit was operated approximately $4.25 \mathrm{~km}$ from the summit (Ampato station/near camera). We give a brief outline here of the instrument setup and retrievals, but thorough discussion of this and alternative methods are given by Kantzas et al. [2010] and McGonigle et al. [2017].

Each UV camera instrument contains two PiCams 
Table 1 - Recent published $\mathrm{SO}_{2}$ flux data for Sabancaya bulk plume.

\begin{tabular}{rcccc}
\hline Study & Duration \& dates & Method & Flux (td $\left.{ }^{-1}\right)$ & 1 s.d. $\mathrm{td}^{-1}$ \\
\hline Carn et al. [2017] & 2015 mean & OMI satellite & 518 & 1600 \\
Moussallam et al. [2017] & 1.5 hrs, Nov 2015 & DOAS & 947 & 332 \\
& & UV camera 1 & 1394 & 352 \\
Kern et al. [2017] & 2 hrs, Apr 2016 & UV camera 2 & 1663 & 318 \\
Ramos Palomino et al. [2016] & Daily means, July-Oct 2016 & DOAS & 890 & 240 \\
Ramos Palomino et al. [2016] & Daily means, Nov 2016 & NOVAC & 1200-7100 & Not reported \\
\hline
\end{tabular}

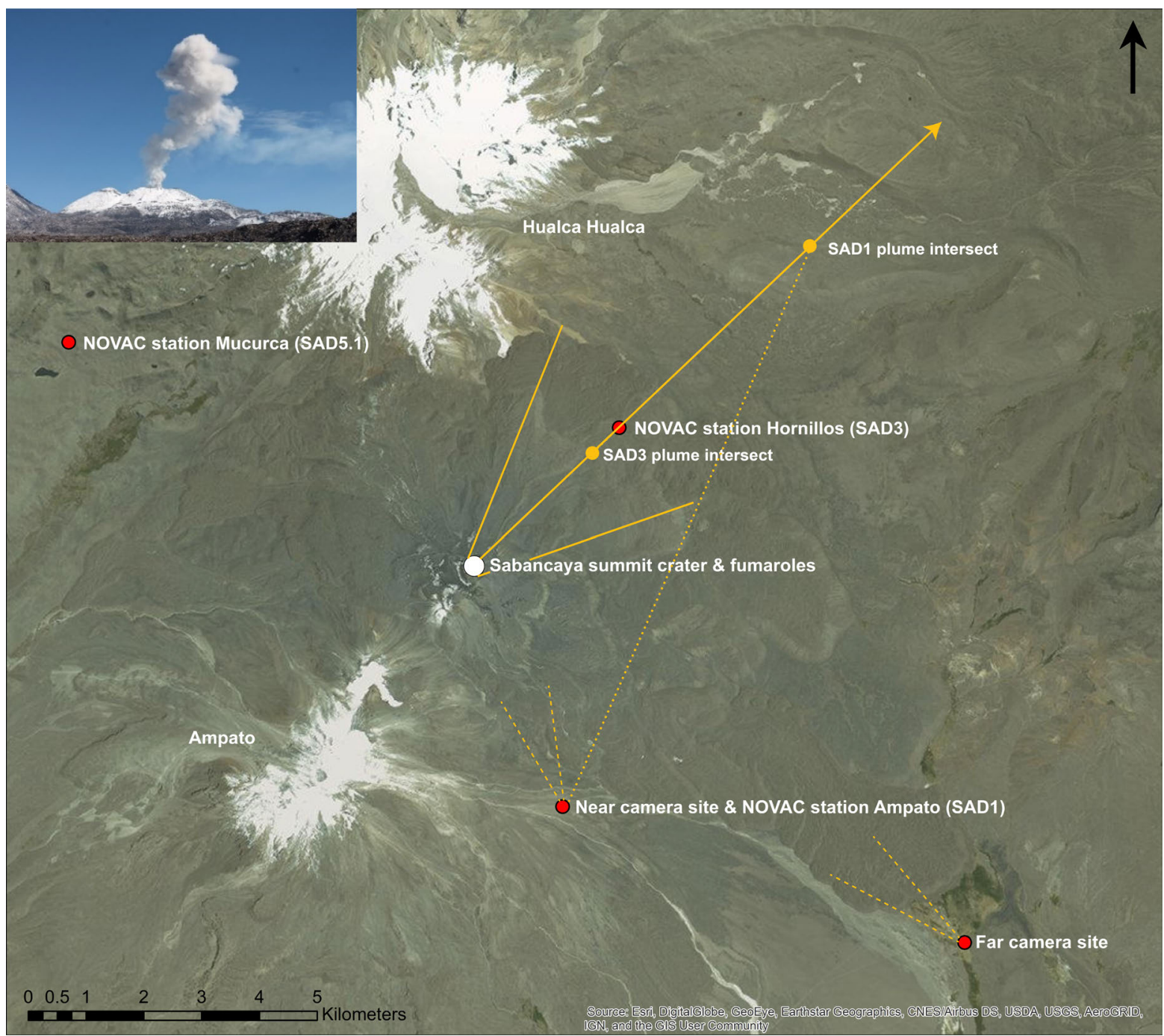

Figure 1: Satellite view of Ampato-Sabancaya complex showing NOVAC installations [Masías Alvarez and Apaza Choquehuayta 2018], infrasound station, UV camera sites from this study, with dashed lines showing camera fields of view at the two camera sites, arrow showing plume direction with additional solid lines indicating the extent reached by the plume from the Sabancaya summit crater during the measurement period, and dotted lines with circles showing NOVAC scan intercept with plume; inset shows the Sabancaya plume viewed from far camera site on 27 April 2018.

with bandpass filters at $330 \mathrm{~nm}$ and $310 \mathrm{~nm} \mathrm{(10} \mathrm{nm} \mathrm{full}$ width at half maximum), the latter of which is an $\mathrm{SO}_{2}$ absorption band commonly used for UV retrievals. Calibration, clear sky, and dark images were collected, and shutter speeds were manually selected for each cam- era. The calibration images used at least three gas-filled quartz cells with known $\mathrm{SO}_{2}$ concentrations (near site: 110, 1000, 2500, 3500, and 4600 ppm; far site: 100, 467, and $1989 \mathrm{ppm}$ ) and showed good linear relationships between known concentrations and apparent ab- 


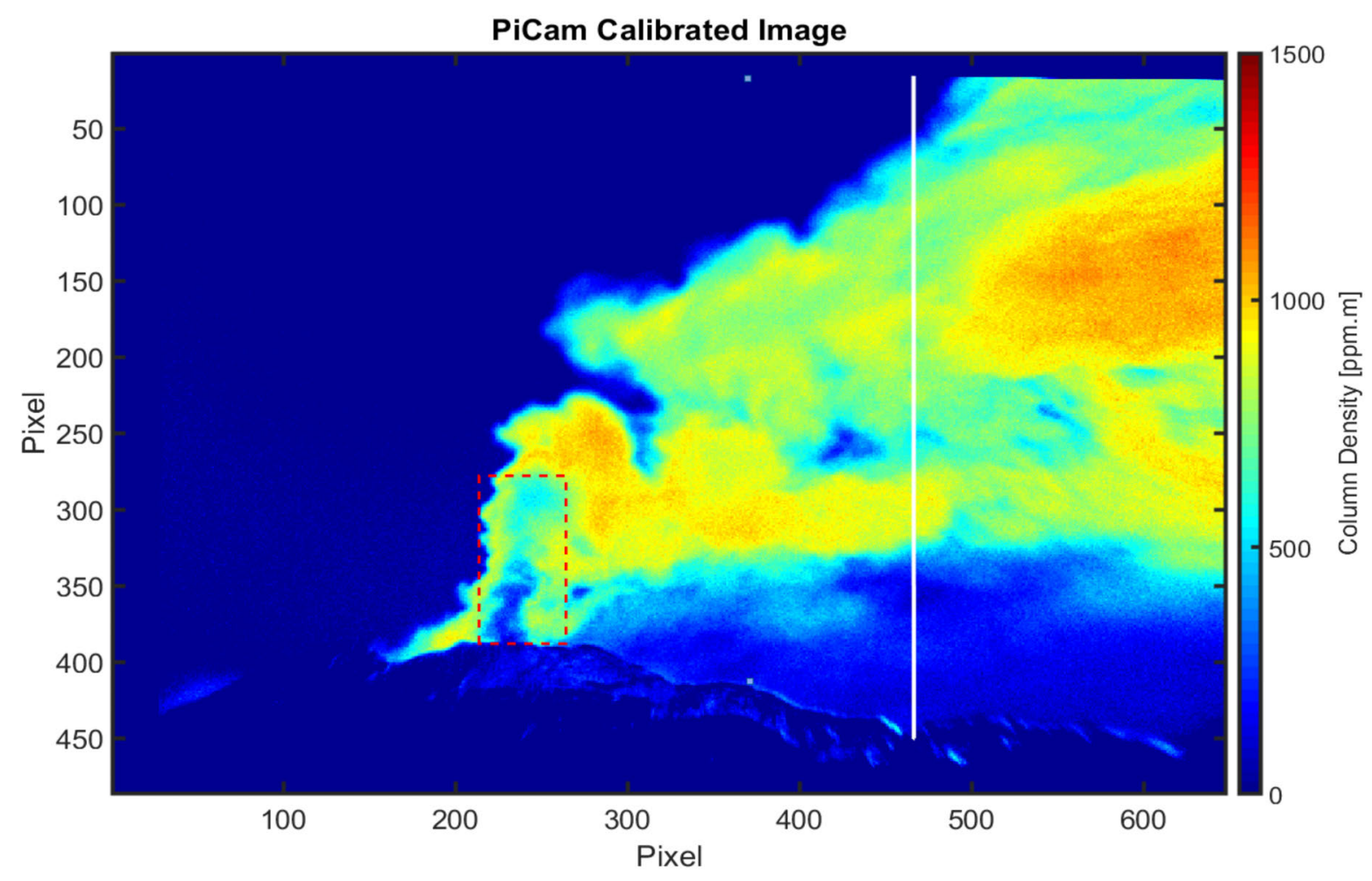

Figure 2: Example of scaled absorbance image from a UV camera; integration line marked in white. Colour bar on right shows calculated column density of $\mathrm{SO}_{2}(\mathrm{ppm} \cdot \mathrm{m})$. At this distance, with a f.o.v of $23.1^{\circ}$, the width of the frame is about $4.2 \mathrm{~km}$. Note the ash-rich central region of the rising plume (rectangle with dashed red line).

sorbance (near site: $r^{2}$ of 0.98 ; far site: $r^{2}$ of 1.00 in calibrations for all data presented here). Acquisition rates were set separately for each camera pair at 0.25 to 0.2 $\mathrm{Hz}$.

Retrievals for integrated column amounts (ICAs) follow Wilkes et al. [2017] using a MATLAB script that permits a plume-free region of the images to be selected for background correction. Column densities (e.g. Figure 2) are integrated along a user-defined plume crosssection to obtain ICAs (in units of $\mathrm{kg} \mathrm{m}^{-1}$ ). Integration lines for the cameras at distance (far camera site) were taken about $1 \mathrm{~km}$ from the crater, where there was less light occlusion by ash from explosions. However, the resulting ICAs and fluxes should be considered lower bounds, as we could not correct directly for light dilution or eliminate the effect of ash. Multiplying the ICA by plume velocity perpendicular to the integration line yields $\mathrm{SO}_{2}$ flux. Velocities used here are based on manual tracking of plume features by following, where possible, high $\mathrm{SO}_{2}$ concentration regions or plume features as they crossed the integration line. Figure 2 shows an example of a calibrated absorbance image with the integration line used for calculating ICAs.

\subsubsection{Light dilution correction}

The quantitative effect of radiation scattering through the atmosphere on optical plume measurements depends on atmospheric conditions in front of the plume (pressure, humidity, and aerosol concentration), distance of the instrument from the plume, and conditions within the plume $\left(\mathrm{SO}_{2}\right.$ concentration, aerosol concentration and composition). Light is scattered differently by air molecules and aerosols, depending on their size relative to the wavelength of the light. Light dilution becomes an issue when a significant portion of the measured radiation is scattered into the field of view in between the plume and the instrument, and thus has not passed through the plume [Mori et al. 2006; Kern et al. 2010]. In UV camera images, this causes systematic underestimation of ICAs [e.g. Bluth et al. 2007; Campion et al. 2018]. The two most recently published methods for correcting light dilution in UV camera images are calibration by co-located DOAS [Kern et al. 2013], which were not available for the data presented here, or correction using scattering coefficients, derived from background intensities of the ground in the same UV camera images [Campion et al. 2015]. The latter method has the advantage of not requiring simultaneous DOAS measurements. However, it requires that the UV images show terrain of constant albedo at varying distances from the camera. With irregular snow cover in our images, it was not possible to find a uniform slope on the ground from which to calculate scattering coefficients. Instead, to estimate the effect of light dilution on our measurements, we compared ICAs along cross sections close to the vent from two time series col- 
lected at near and far measurement sites. Over the 7minute overlap between the datasets, ICAs along these cross sections are about 1.7 times higher at the near site (Figure 3). The relationship between ICAs at different distances can be used to calculate an extinction coefficient and estimate the effect of light dilution [Bluth et al. 2007; Lübcke et al. 2013; Smekens et al. 2015a]. Following Lübcke et al. [2013, Appendix D], this ratio and the difference in distance to the plume is used to calculate an extinction coefficient of $0.0878 \mathrm{~km}^{-1}$. This coefficient represents the loss in measured column amounts due to light dilution with distance. We use the same process to determine that column amounts and fluxes measured at $10.3 \mathrm{~km}$ distance from the plume could be underestimated by a factor of 2.5. At a distance of 4.25 $\mathrm{km}$ from the plume, this factor is lower at 1.5 , but still indicates a significant effect from light dilution.

We also note that the integration line used for this calculation was not the same as that used for flux determination. We needed to select a line visible from both near and far cameras and were thus restricted by the field of view of the near camera to a distance about 600 $\mathrm{m}$ from the vent. However, the plume ash content and condensation of emitted water vapour are expected to give a higher optical thickness here than farther downwind, potentially also affecting scattering. Therefore, we used an integration line $1 \mathrm{~km}$ downwind of the vent for our final flux estimates. One sequence from camera B (see results), had a field of view slightly further downwind, and thus further from the plume. The exact distance is unknown as there are no geographical features in these images to which the distances can be referenced. We therefore used the same light dilution factor for all sequences taken from the far camera site. We consider this an acceptable estimate since, for an integration line $3 \mathrm{~km}$ downwind, the distance from the far camera site to the plume is about $10.5 \mathrm{~km}$. The light dilution factor does not change significantly from that at $10.3 \mathrm{~km}$ and mean fluxes for this sequence would increase by less than $0.5 \mathrm{~kg} \mathrm{~s}^{-1}$. For comparison, light dilution for Sabancaya was modelled by Kern et al. [2017] to affect their DOAS measurements by about $10 \%$, and Moussallam et al. [2017] estimated up to $38 \%$ for their UV camera measurements at a distance of $4.1 \mathrm{~km}$ from the plume, under different measurement conditions.

\subsection{NOVAC data}

The NOVAC installation at Sabancaya [Masías Alvarez and Apaza Choquehuayta 2018] includes three DOAS instruments located around the volcano (Figure 1). Data were available for two of these and are presented here for comparison. The plume was roughly over Hornillos during these measurements, with the scan plane intersecting the plume about $3 \mathrm{~km}$ downwind, while the near UV camera site was at Ampato at a much greater distance of about $11 \mathrm{~km}$ from the plume (8 $\mathrm{km}$ downwind). Flux calculations used the NOVAC software (available at https://novac-community.org/), assuming plume heights of $1 \mathrm{~km}$ above the scanner and a windspeed model from the National Oceanic and Atmospheric Administration (NOAA) through the Global Data Assimilation System (GDAS). The 1-degree database (GDAS1) has a spatial resolution of 1 decimal degree, with data gathered three times per hour at pressure increments of $50 \mathrm{hPa}$ and includes corresponding height, wind direction, and windspeeds. Windspeeds during the scanning periods are derived from linear interpolation between two windspeeds directly above the vent at the plume height, three hours apart. UV camera images show the base of the plume at about $1 \mathrm{~km}$ above the ground at the furthest distance from the vent visible in images (close to, but not at, the SAD3 plume intersect), so we consider this a reasonable estimate. Further details of the retrieval procedure can be found in the Supplementary Materials.

\subsection{Infrasound data}

Over the last two decades, infrasound (atmospheric acoustic waves with frequencies $<20 \mathrm{~Hz}$ ) has emerged as a powerful and robust tool for volcano monitoring [Fee and Matoza 2013]. Among the numerous natural processes that can generate acoustic waves, volcanoes are prolific radiators of infrasound, in particular when large volumes of gas and ash are violently ejected into the atmosphere. The use of infrasound for volcano monitoring in the near-field $(<10 \mathrm{~km})$ has become increasingly popular due to its unmatched temporal resolution [Johnson 2004]. Infrasound applications include detecting, locating and tracking explosive volcanic eruptions, and recent efforts towards providing estimates of eruption source parameters hold promising results [De Angelis et al. 2019].

At Sabancaya, data from one permanent infrasound station (Figure 1) were available during the UV camera measurement period. The station recorded at $100 \mathrm{~Hz}$ and 24-bit resolution using an iTem prs100 microphone [Delle Donne and Ripepe 2012]. The acoustic fingerprint of major explosions (i.e. those reported by the observatory) at Sabancaya, from infrasound data recorded outside of the measurement period, is characterized by relatively low excess pressures $(<10 \mathrm{~Pa})$ lasting an average of 1-3 minutes. Typical waveforms show an initial compression followed by a sustained complex coda, probably shaped by the turbulence of the plume. However, no major explosions with these typical waveforms were registered during the UV camera measurements.

\section{Results AND Discussion}

Over nearly two hours of measurements, several discrete pulses of ash and gas were observed (see Supplementary Materials for an example UV camera absorbance video). Passive degassing continued between 

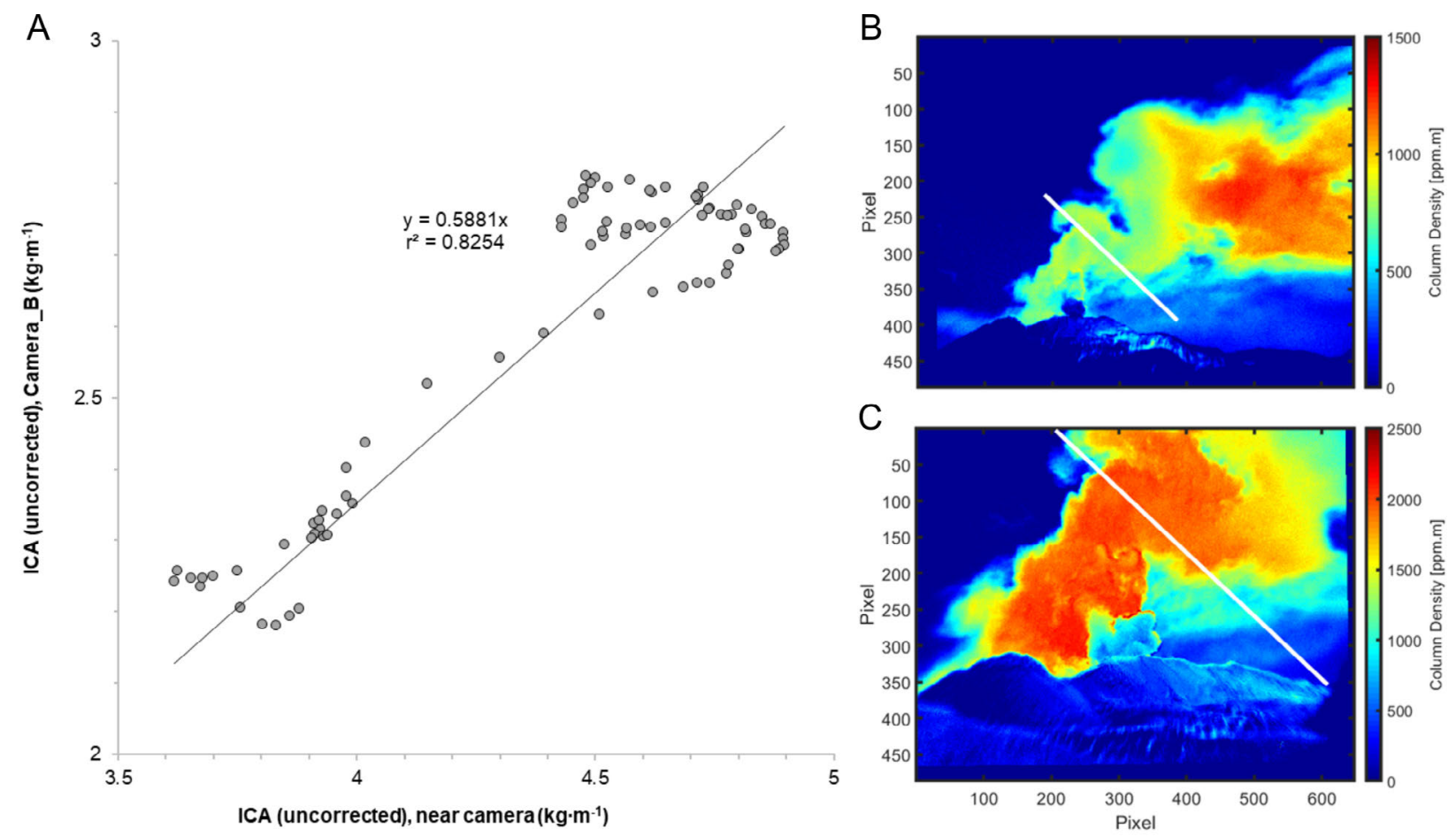

Figure 3: Light dilution is estimated using [A] the relationship between ICAs at [B] far and [C] near sites as explained in the text. Masses were calculated along an integration line that is visible in both sets of absorbance images, selected to also minimize interference from the central column of ash; [B] images at 15:07:00 UTC from Camera B at the far site and [C] from the near site camera; the start of an eruption pulse is visible in both images, where column density appears lower due to ash; note that images have different colour scales and different viewing angles.

these emission events.

The time series flux data from three UV camera sequences and NOVAC scanners at Sabancaya are shown in Figure 4. Two camera sequences from cameras A and $\mathrm{B}$ were taken with the vent at the centre of the image, while another sequence from camera B was taken fully in the plume. As this field of view corresponds to a lag of several minutes in the time stamps, a fourth sequence from Camera A was used to match it to the previous time series. This shows the plume, and retrieved data capture the same trends in degassing; however, this sequence was excluded from quantitative analyses due to features appearing in the background, likely caused by reflections from an object in the near-field.

The UV camera-derived fluxes after corrections for light dilution (mean of $27.1 \mathrm{~kg}^{-1}$ ) extrapolate to a daily mean of about $2340 \mathrm{td}^{-1}$, nearly double that of recent UV camera and DOAS measurements (Table 1) made before the onset of the current eruptive episode in November 2016. The decline in apparent fluxes towards the end of the measurement period is due to clouds in the field of view (Figure 4, grey shading), and data from 15:28:30 UTC onwards are excluded from these calculations for this reason. Ash is visible crossing the integration line around 14:29:00 UTC (Figure 4, grey shading), following an ash-rich pulse. This is likely to cause underestimation during the correspond- ing peak in $\mathrm{SO}_{2}$ fluxes. Coincident scan fluxes from Hornillos NOVAC station are very similar to those from the UV cameras, averaging $2266 \mathrm{td}^{-1}$ with a standard deviation of $\pm 472 \mathrm{td}^{-1}$ over the measurement period of about $1.5 \mathrm{hrs}$. NOVAC fluxes from the scanner at Ampato for our measurement period are lower than the UV camera fluxes, averaging $1394 \mathrm{td}^{-1}$. The comparison also shows the advantage of the UV cameras' higher temporal resolution, which permits identification of individual gas pulses in time series data. This is largely due to the frequency of imaging compared to DOAS scan times (yielding a flux measurement about every 15 minutes). The ability to select camera integration lines close to the vent also helps in distinguishing individual events before the plume mixes downwind.

\subsection{Sources of uncertainty in UV camera and NOVAC methods}

Fluxes obtained by the NOVAC scanner at Hornillos are consistent with those from the UV camera measurements, with the exception of short-term variations that the scanner was not able to capture due to its limited data acquisition rate. Next, we outline reasons for the mismatch between these data and the lower fluxes recorded at the Ampato NOVAC station, followed by a discussion of potential sources 


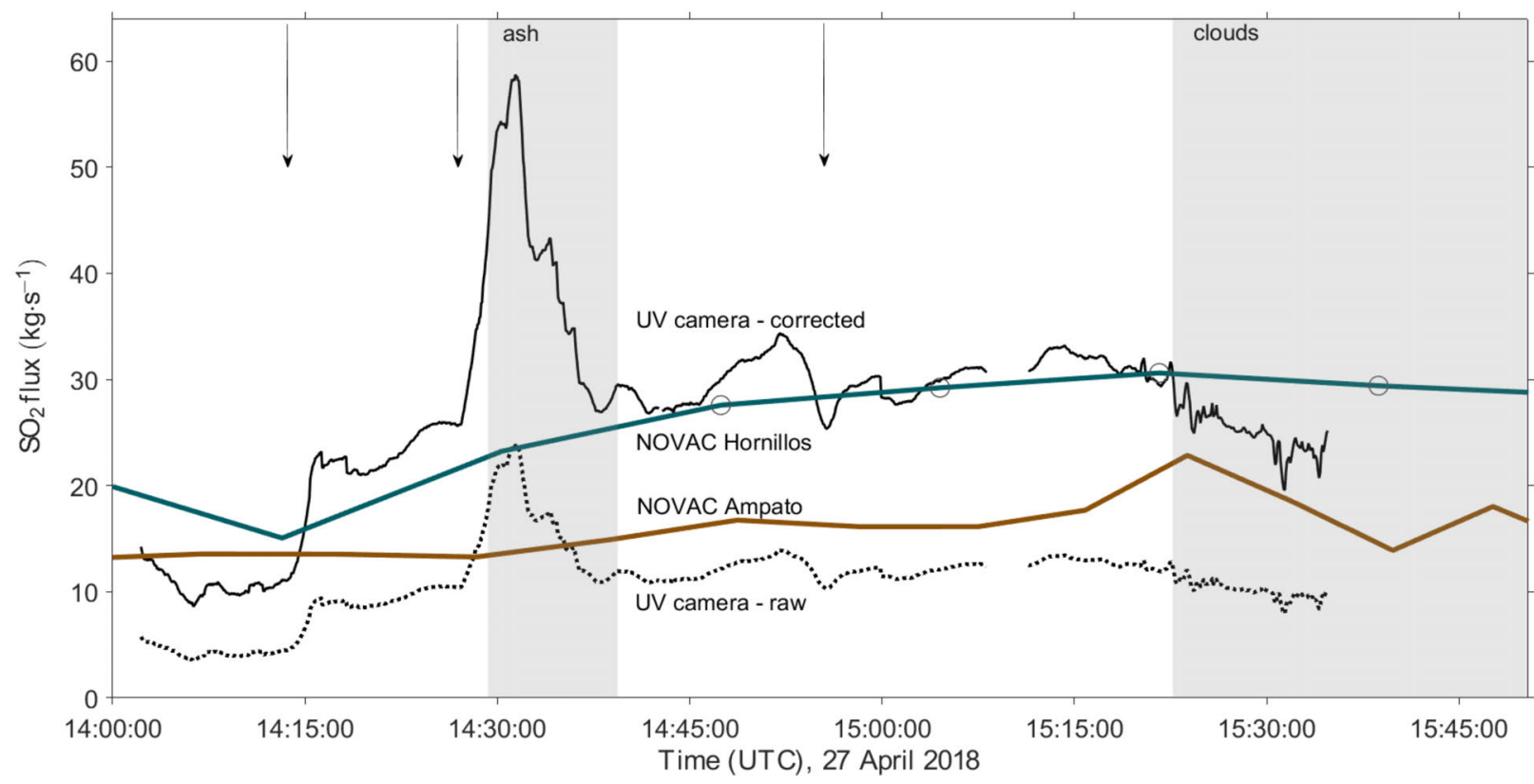

Figure 4: Retrieved raw and light-dilution-corrected $\mathrm{SO}_{2}$ fluxes from two UV cameras at far camera site, and two NOVAC scan sites. Note that the first two UV camera sequences are from integration lines about $1 \mathrm{~km}$ downwind (camera A from 14:03 to 14:41 and camera B from 14:41 to 15:08), while the last sequence (camera B from 15:11 UTC onwards) is calculated further downwind in the plume. An additional sequence, which is not shown as a variable background affected retrieved ICAs, was used to match the time stamps across these sequences. Points marked with grey circles indicate scans for which the NOVAC software retrieved a plume completeness $>85 \%$, indicating the entire plume was likely captured. Grey shaded boxes indicate times when retrievals may be affected by ash and cloud, as labelled on the plot, causing underestimation of flux. Vertical arrows indicate times when the first pulse of gas from an explosion crosses the integration line for the UV cameras, corresponding to times indicated in Table 2, for the three explosions where this first gas pulse can be isolated. Note that this occurs several minutes after the explosion gas pulse first appears above the vent.

of error and uncertainty-namely, light dilution and wind velocity - that are important considerations in obtaining reliable measurements of $\mathrm{SO}_{2}$ flux by either method.

The explanation for the lower fluxes at Ampato station compared to that at Hornillos is twofold. Firstly, the location of Ampato station, to the south-southeast of the active vent, was unfavourable for capturing the gas plume at the time of measurement. The instrument's orientation is such that the scanning plane intersects the plume at fairly low scan elevation angles (often $>75$ degrees from zenith). It is therefore likely that part of the plume was behind the visible horizon and was missed by the instrument. Based on an automatic plume characterization scheme incorporated in the NOVAC software, the plume completeness was determined to be less than $85 \%$ for all Ampato measurements (Figure 4). Plume completeness is one of the main criteria used by observatories to assess the quality of NOVAC data, and measurements with low plume completeness would normally be filtered out and not reported. However, we elect to show the data here in order to discuss the limitations of the measurements.

Secondly, light dilution is also expected to significantly affect the measurements from Ampato. The instrument's conical scanning plane intersected the plume at an oblique angle $11 \mathrm{~km}$ from the vent (Figure 1). At such great distances, light will enter the field of view between the plume and the instrument and dilute the measured absorption signal, despite the relatively clear conditions in the high-elevation Peruvian desert. Kern et al. [2010] showed that dilution by pure Rayleigh scattering in the absence of any atmospheric aerosols could lead to about a $35 \%$ reduction in measured $\mathrm{SO}_{2}$ column densities at a distance of $5 \mathrm{~km}$ (see their Figure 4). However, this number was calculated for sea-level conditions. Given that our Sabancaya measurements were made at approximately half the pressure of sea-level, we expect a similar dilution would occur at about twice the plume distance. Therefore, the differences between our results from Ampato and those obtained by the Hornillos scanner directly beneath the plume are in qualitative agreement with this rough estimate of light dilution.

Without more detailed information on atmospheric and plume conditions at the time of the measurements, we cannot isolate these effects to identify whether incomplete plume scans or light dilution was dominant in causing the discrepancy between the Ampato and Hornillos measurements, but both likely contribute to 
some degree. We also know that the measurements at Hornillos are expected to be more representative of the true emission rates due to the favourable location of the scanner directly beneath the plume, thus minimizing the impact of either of these error sources. It is therefore reassuring that the UV camera measurements are consistent with these data after the images have been corrected for light dilution.

Correcting for light dilution is still key, however, particularly at several kilometres' distance from the plume, as demonstrated here. For UV camera images, unless the field of view includes ground surfaces suitable for corrections following Campion et al. [2015] or co-located DOAS data are available, corrections require images taken at different distances. Using multiple UV cameras for simultaneous data capture has enabled us to estimate light dilution by this method as well as to track features through the plume. We note that our light dilution estimate is based on a brief overlap of 7 minutes (81 data points) but for longer time series with changing atmospheric conditions, the methods mentioned above [Kern et al. 2013; Campion et al. 2015] would provide continuous correction factors and may be simpler than operating two cameras continuously.

Inconsistent windspeed information is another potential source for discrepancies between our data streams. Despite the good match between UV camera and Hornillos NOVAC data, the absolute windspeeds used with NOVAC are about 1.6 times higher than the perpendicular speed component derived from manual plume tracking in the UV camera images, with a median of $4.8 \mathrm{~m} \mathrm{~s}^{-1}$ compared to $2.9 \mathrm{~m} \mathrm{~s}^{-1}$, respectively (means of 4.8 and $3.1 \mathrm{~m} \mathrm{~s}^{-1}$, respectively). Such a discrepancy would be expected if the plume were not perpendicular to the camera's viewing plane. However, the scanning data suggest that the plume was generally over the Hornillos station during the measurement period, a configuration that would lead to a nearperpendicular view by the cameras.

Other possible explanations for this discrepancy in windspeed are (1) that the windspeed given by the GDAS model is too high and/or (2) that the plume changes speed and/or direction on its path between the summit vent and the NOVAC station. It is important to note that the 1-degree grid of the GDAS is too coarse to account for atmospheric dynamics caused by topographic features such as the edifice of the Ampato/Sabancaya volcanic complex. Such features might cause significant disruptions to the large-scale wind field, potentially affecting both speed and direction on local to regional scales. Given the agreement between the fluxes calculated for both instruments, it is possible in this example that the scale of the GDAS-1 model data was appropriate for the measurement profile of the NOVAC scan and to capture changes in windspeed or plume spreading at the scan location. Finally, second-order errors can be induced by variations in the camera's viewing angle relative to the plume direction across the image sensor [Klein et al. 2017] However, this effect should be very minor given our nearly perpendicular viewing geometry and the fact that we performed our manual tracking of the plume near the centre of the images.

It is unclear whether uncertainties in windspeed affected our comparison in a significant way, but this discussion highlights the importance of accurate windspeed and wind direction information when analyzing scanning DOAS data. In situations where NOVAC scanners are outfitted with dual spectrometers, the plume is directly over the instruments and travelling in a consistent direction, and the telemetry link between the observatory and the NOVAC station is functional, the NOVAC instruments can determine the plume speed using a dual-beam correlation approach [Galle et al. 2010]. However, these conditions are often not met and, as is the case here, alternate approaches for obtaining accurate wind information are often required. Our experiment shows that simple, inexpensive UV cameras co-located with NOVAC scanners could in many situations provide more accurate windspeed data for analysis of $\mathrm{SO}_{2}$ emission rates than is often available from other sources. Although deriving fluxes from the UV camera would require calibration to changing conditions, no calibration is required for tracking plume movement. Further experiments with co-locating UV cameras and scanning DOAS would be required to understand how this would be implemented. Specifically, to obtain windspeed at the same transect as the $\mathrm{SO}_{2}$ ICAs, the camera field of view would need to include the possible DOAS scan planes. We note that in the example presented, a direct multiplication of UV cameraderived windspeed with NOVAC scan data would result in lower fluxes than those reported here-whether from the UV camera, or from NOVAC scans with modelled NOAA windspeeds-likely because of the difference in the scan transect compared with the camera transect used for column amounts and windspeed.

\subsection{Eruptive activity}

Visual observations suggest that ash and gas emission events during the measurement period are explosions; however, infrasound data during the observation period do not show clear discrete explosions above the level of noise, and we note that noise levels are particularly high from 15:18:00 UTC, coinciding with changing weather conditions. In the images, pulses of ash appear frequently (up to 2-3 times per minute) above the top of the summit, and in calculating gas masses for these pulses, we assume that the combined ash and gas emissions that produce discrete pulses in the vertical column are single events.

One instance of acoustic chugging occurs at 14:14:55-14:15:10 UTC, preceding a large increase in $\mathrm{SO}_{2}$ degassing (Figure 5). Chugging is a sequence of simple acoustic (and sometimes seismic) pulses 
Table $2-\mathrm{SO}_{2}$ masses for gas pulses. Time of appearance above vent, time that the leading edge and back of the gas pulse cross the integration line, and gas masses adjusted for estimated light dilution are also listed. Note that the $\mathrm{SO}_{2}$ masses for the three pulses from 14:14:04 UTC are a mean, as degassing is sustained over this period and pulses could not be separated. Masses are rounded to 3 s.f; see Supplementary Materials for details of calculations.

\begin{tabular}{cccccc}
\hline $\begin{array}{c}\text { Time of emitted } \\
\text { pulse (UTC) }\end{array}$ & Instrument & $\begin{array}{c}\text { Pulse leading } \\
\text { edge (UTC) }\end{array}$ & $\begin{array}{c}\text { Pulse back } \\
\text { (UTC) }\end{array}$ & $\mathrm{SO}_{2}$ mass $(\mathrm{kg})$ & $\begin{array}{c}\text { Adjusted } \\
\mathrm{SO}_{2} \text { mass }(\mathrm{kg})\end{array}$ \\
\hline$?$ & Camera A & $14: 13: 36$ & $14: 26: 20$ & 3340 & 8240 \\
$14: 14: 04$ & Camera A & $14: 26: 24$ & $14: 42: 36$ & 1390 & 3430 \\
$14: 19: 56$ & & (first pulse) & (last pulse) & 1390 & 3430 \\
$14: 25: 44$ & & & & 1390 & 3430 \\
$14: 33: 56$ & Camera B & $14: 55: 40$ & $15: 08: 08$ & 1200 & 2950 \\
\hline
\end{tabular}

recorded at regular and short intervals. Such signals have been often linked to degassing pulses in open vent systems [e.g. Lees and Ruiz 2008]. It appears that the initial increase in $\mathrm{SO}_{2}$ flux at 14:13 UTC is at least partially associated with an event that occurred before the start of the measurement sequence, as it takes 10-20 minutes for gas emissions to cross the UV camera integration line. Ash and a vertical $\mathrm{SO}_{2}$ column are visible at the start of our image sequence that support this increase in $\mathrm{SO}_{2}$ being caused by a discrete pulse. However, background flux remains elevated and appears to increase throughout the sequence following this, due either to the frequency of ash and gas pulses or to sustained passive degassing. Both this background increase and the high fluxes in the subsequent gas pulses (the first of which is detected at 14:26) may be linked to the chugging signal.

As parts of the plume move at different speeds, gas from a single event cannot be cleanly isolated, but tracking of $\mathrm{SO}_{2}$-rich pulses as they move horizontally in UV camera absorbance videos, together with peaks in the calculated $\mathrm{SO}_{2}$ flux, allows us to estimate gas mass from some discrete events (see Supplementary Materials for calculations). Increases in flux are observed following each emission event and, while it was necessary to exclude the later data due to clouds crossing the integration lines from around 15:18:05 UTC, some of our data capture the contrast between background degassing and the $\mathrm{SO}_{2}$ flux associated with an event (Table 2). Emitted masses were calculated by summing the fluxes (in kilograms per second) over the time taken for each gas pulse to cross the integration line. For each measurement, the lowest flux before or after the pulse was subtracted, as it was assumed to represent background degassing. For five events, the masses corrected for light dilution range from about $2950 \mathrm{~kg}$ to $8240 \mathrm{~kg}$. Given the potential for underestimation of emissions when imaging optically thick plumes [Kern et al. 2013] and the fact that there is ash clearly visible crossing the integration line, the actual masses may be higher than these estimates. It is also possible that chugging occurring early in the sequence may have caused an elevated background $\mathrm{SO}_{2}$ flux from about 14:26 to 14:52 UTC, affecting the three pulses observed over this period and that the reported masses are not fully corrected for increased background degassing.

The activity at Sabancaya during the measurement period is characterised by sustained gas emissions with additional discrete pulses of gas and ash. The infrasound data show a lack of overpressure. Juvenile ash sampled earlier in the eruption, during 2017, was andesitic [Manrique et al. 2018], and previous eruptions have been andesitic-to-rhyolitic [Samaniego et al. 2016]. Ballistics were reported in 2017; activity at the time was described as vulcanian, with a transition in ash composition after vent-clearing wherein the proportion of lithics decreased while that of juvenile material increased [Manrique et al. 2018]. INGEMMET reports that seismic activity during the week of 23 April was dominated by long period earthquakes and tremor, with few hybrid earthquakes [OVI-INGEMMET \& IGP 2018].

Sustained $\mathrm{SO}_{2}$ degassing during the measurement period suggests an open vent, with gas sourced from within the conduit. The lack of ballistics, which could indicate fragmentation of a sealed conduit, also supports an open conduit. Erupted magma appears to be solely in the form of ash, which could be juvenile or remobilised from earlier explosions. The pulses of increased gas and ash emission indicates a fluctuating gas supply. The $\mathrm{SO}_{2}$ fluxes reported during similar eruptive episodes at other volcanoes typically focus on explosions, which we did not capture in our measurements at Sabancaya. Nonetheless, the observed activity merits comparison to other volcanoes due to the high $\mathrm{SO}_{2}$ fluxes and to the fact that it occurs between, and may be related to the processes that cause, frequent explosions.

The $\mathrm{SO}_{2}$ masses we measure during the pulses at Sabancaya are significantly higher (2.95-8.24t) than those reported from explosions with some similar characteristics at Karymsky volcano [1.05-1.53 t; Fischer et al. 2002] Santa María volcano (Santiaguito dome complex) [0.37-1.27 t; Holland et al. 2011] or Gunung Semeru [0.2-1.46 t; Smekens et al. 2015b]. At these volcanoes, explosive events (which are also characterised by 

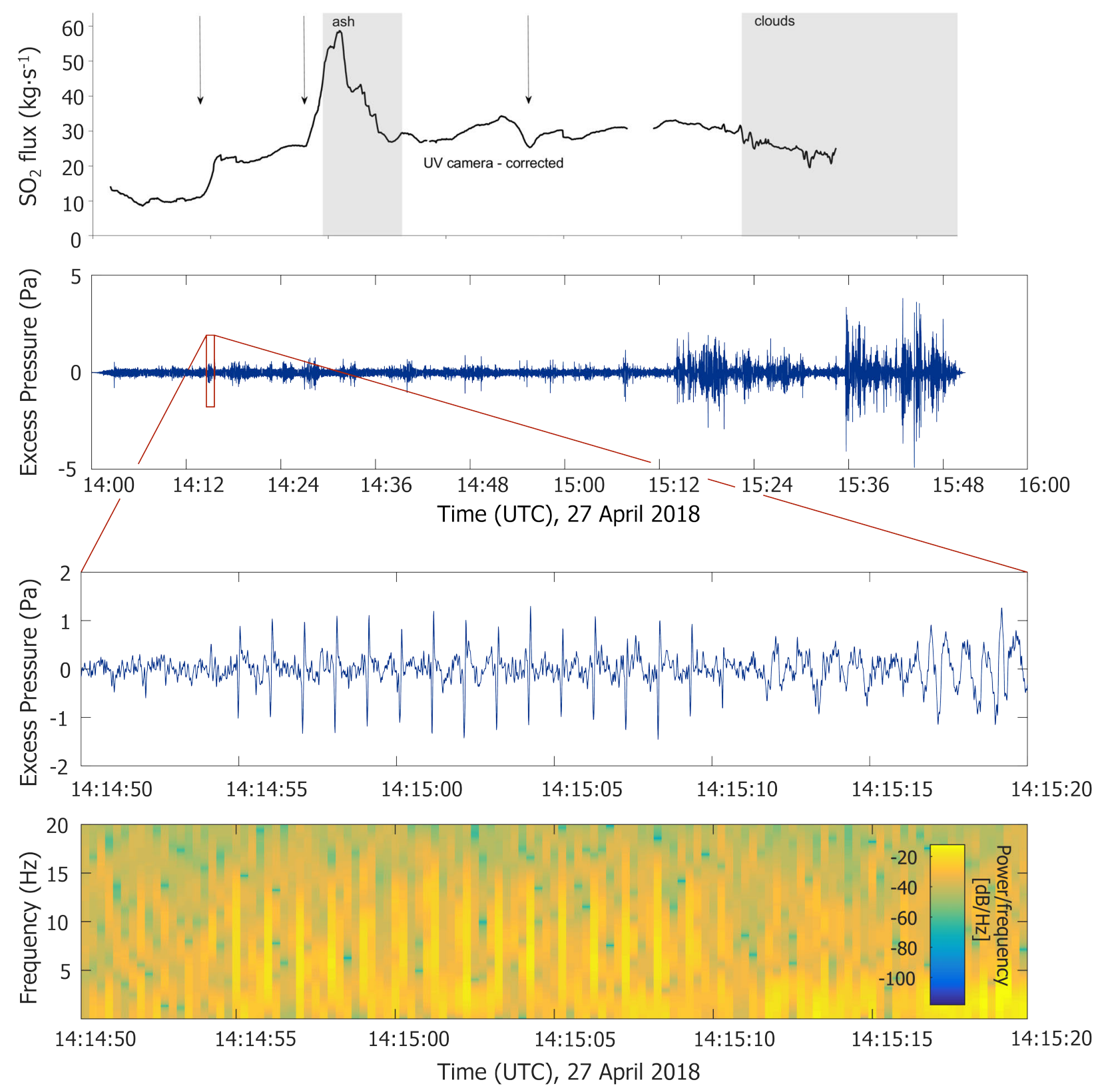

Figure 5: Acoustic infrasound data recorded on 27 April 2018 during UV camera observations $\left(\mathrm{SO}_{2}\right.$ flux in top panel, infrasound in second panel from top); no explosion signals are observed above the level of noise. Expansion shows infrasound waveforms (third panel from top) and spectrogram (bottom panel) of a chugging sequence potentially associated with gas puffing or the occurrence of small bubble explosions (colour scale indicates relative power/frequency). Chugging coincides with sustained increases in $\mathrm{SO}_{2}$ flux after the first gas pulse detected in UV camera data at 14:14 UTC.

discrete pulses of gas) are attributed to viscous plug formation followed by overpressure from buildup of gas and magma causing rupture [Fischer et al. 2002; Holland et al. 2011; Smekens et al. 2015b]. Smekens et al. [2015b] identify two clusters of higher and lower $\mathrm{SO}_{2}$ masses in explosions at Semeru, and link the higher masses to longer duration explosive events lasting about 15 minutes with multiple pulses and sustained increases in degassing. While pulses are not clearly visible in $\mathrm{SO}_{2}$ fluxes measured $1 \mathrm{~km}$ down-vent at Sabancaya, the duration and magnitude of the events, with multiple pulses of ash visible in the absorbance images, has some similarity to this description. The mechanism for explosions with multiple pulses proposed by Smekens et al. [2015b] is higher magma supply rate compared to single explosions. Campion et al. [2018] measured $\mathrm{SO}_{2}$ masses of 1.3-6.9t from explosions at Popocatéptl. They propose that 'gas slug' rise and coalescence within a permeable fracture network, kept open by high passive degassing flux, could account for this type of behaviour. This implies that a decrease in degassing could cause sealing of the conduit frac- 
tures, leading to a larger explosion. However, we are limited in interpreting the eruption mechanisms at Sabancaya by a lack of information about the magma rheology and our relatively short dataset, which does not characterise the full range of activity at Sabancaya during the current eruptive episode. Specifically, our gas data do not capture any of the explosions detected in the seismic data, and this transition could be important to understanding the eruption mechanisms. The high $\mathrm{SO}_{2}$ masses associated with the observed pulses may relate to conduit processes following previous explosions. For example, chugging at Karymsky has been proposed to result from depressurisation in the conduit and continued degassing after an explosion [Johnson et al. 1998]. We also cannot rule out the possibility that multiple conduits and vents are present [e.g. Nadeau et al. 2011], such that active and passive degassing occur simultaneously through separate pathways.

\section{Conclusions}

Our comparison of UV camera and NOVAC DOAS data highlight the advantages and limitations of the two techniques. While the NOVAC scanners operate continuously without need for user interaction, typically measure the plume further downwind where ash is less of a concern, and provide full spectral information, the UV cameras provide higher time resolution and images from which plume speed can be calculated directly. This allowed us to identify $\mathrm{SO}_{2}$ emissions associated with individual gas pulses at Sabancaya that could not be detected in the DOAS data.

Windspeeds generated by the NOAA GDAS1 model and used with the NOVAC data were, on average, 1.6 times higher than those manually estimated from tracking plume motion on camera images. Since the camera direction is approximately perpendicular to the plume, this discrepancy suggests that the model may have overestimated windspeeds above the NOVAC scanners. This is concerning, given that errors in the windspeed linearly affect retrieved emission rates. The 1-degree grid and the low temporal resolution may not have captured local and short-term variations in windspeed. Even if our measurements at Sabancaya were not severely affected, obtaining accurate wind speeds is challenging with DOAS scanners alone, and requires several specific conditions. Instead, co-location of UV cameras with permanent DOAS scanners-ideally, viewing perpendicular to the scan plane-could prove to be the best approach to obtaining independent local plume speed estimates.

Light dilution remains a challenge that both techniques must overcome to obtain accurate results. For the UV camera data collected in this study, light dilution could be estimated due to the availability of simultaneous imagery at different distances, with scope for error due to the angle of the plume and variations over time. However, locating cameras at different distances may not always be efficient, and further approaches to dealing with dilution effects, or at least filtering poor data, should be explored.

Finally, our data show a $\mathrm{SO}_{2}$ emission rate of about $27 \mathrm{~kg} \mathrm{~s}^{-1}$ at Sabancaya during the measurement period, with sustained $\mathrm{SO}_{2}$ degassing as well as discrete pulses with higher $\mathrm{SO}_{2}$ masses and ash.

\section{Acknowledgements}

TI is a Commonwealth Rutherford Fellow, supported by the UK government. AJSMcG acknowledges the support of Rolex, and TDP a Royal Society Research Grant (RG170226). ADM is funded by NERC Grant NE/P00105X/1. FA acknowledges the support of the PCI-CONICYT project REDES170174. FA and FR acknowledge the support of Proyectos Especiales 2017 Vicerrectoría de Investigación y Desarrollo Tecnológico de la Universidad Católica del Norte "Procesos que controlan el balance de masa en volcanes activos del norte de Chile". SL is funded by a CONICYTPCHA/Doctorado Nacional/2016- 21160276 scholarship.

The USAID Office of Foreign Disaster Assistance is gratefully acknowledged for its support of the 2018 NOVAC workshop. We thank Patricia Nadeau and Simon Carn for their insightful reviews.

\section{Author Affiliations}

$\alpha$ Department of Geography, University of Sheffield, UK. $\beta$ Instituto Geológico Minero y Metalúrgico, Lima, Perú. $\gamma$ Cascades Volcano Observatory, U.S. Geological Survey, Vancouver, WA, USA.

$\delta$ Department of Earth, Ocean E Ecological Sciences, University of Liverpool, UK.

$\varepsilon$ Ckelar Volcanes - Núcleo de Investigación en Riesgo Volcánico, Universidad Católica del Norte, Antofagasta, Chile. $\zeta$ Programa de Doctorado en Ciencias mención Geología, Universidad Católica del Norte, Antofagasta, Chile.

$\eta$ Departamento de Ciencias Geológicas, Universidad Católica del Norte, Antofagasta, Chile.

$\vartheta$ Instituto Geofísico de la Escuela Politécnica Nacional, Quito, Ecuador.

เ School of Geosciences, The University of Sydney, Sydney, NSW 2006, Australia.

$\kappa$ Faculty of Health, Engineering and Sciences, University of Southern Queensland, Toowoomba, QLD 4350, Australia.

\section{Author CONTRIBUtions}

UV camera images were collected by TP, TW, FAC, SL, FR, FA, and FV, and processed by TI using code written by TW. Infrasound data were provided by ADM 
and SDA. NOVAC data were provided and processed by FAC and CK. The manuscript was written by TI, CK, $\mathrm{TP}$, and $\mathrm{AJSMcG}$.

\section{Data aVailability}

Absorbance videos and details of additional data analyses are available in the Supplementary Materials alongside the online version of this article. Unprocessed data can be provided on request.

\section{Copyright NOTICE}

(C) The Author(s) 2019. This article is distributed under the terms of the Creative Commons Attribution 4.0 International License, which permits unrestricted use, distribution, and reproduction in any medium, provided you give appropriate credit to the original author(s) and the source, provide a link to the Creative Commons license, and indicate if changes were made.

\section{REFERENCES}

Bluth, G., J. Shannon, I. Watson, A. Prata, and V. Realmuto (2007). "Development of an ultra-violet digital camera for volcanic SO2 imaging". Journal of Volcanology and Geothermal Research 161.1-2, pp. 47-56. Dor: $10.1016 / \mathrm{j}$. jvolgeores.2006.11.004.

Burton, M., G. Salerno, L. D’Auria, T. Caltabiano, F. Murè, and R. Maugeri (2015). "SO 2 flux monitoring at Stromboli with the new permanent INGV SO 2 camera system: A comparison with the FLAME network and seismological data". Journal of Volcanology and Geothermal Research 300, pp. 95-102. Dor: 10 . 1016/ j . jvolgeores.2015.02.006.

Campion, R., H. Delgado-Granados, D. Legrand, N. Taquet, T. Boulesteix, S. Pedraza-Espitıa, and T. Lecocq (2018). "Breathing and Coughing: The Extraordinarily High Degassing of Popocatépetl Volcano Investigated With an SO2 Camera". Frontiers in Earth Science 6. DoI: 10.3389/feart.2018.00163.

Campion, R., H. Delgado-Granados, and T. Mori (2015). "Image-based correction of the light dilution effect for SO 2 camera measurements". Journal of Volcanology and Geothermal Research 300, pp. 48-57. Dor: 10. 1016/ j . jvolgeores.2015.01.004.

Carn, S. A., V. E. Fioletov, C. A. McLinden, C. Li, and N. A. Krotkov (2017). "A decade of global volcanic SO2 emissions measured from space". Scientific Reports 7.1. Dor: 10.1038 / srep44095.

D'Aleo, R., M. Bitetto, D. D. Donne, G. Tamburello, A. Battaglia, M. Coltelli, D. Patanè, M. Prestifilippo, M. Sciotto, and A. Aiuppa (2016). "Spatially resolved SO2 flux emissions from Mt Etna". Geophysical Research Letters 43.14, pp. 7511-7519. Dor: 10 . 1002 / $2016 \mathrm{gl} 069938$.
De Angelis, S., A. Diaz-Moreno, and L. Zuccarello (2019). "Recent Developments and Applications of Acoustic Infrasound to Monitor Volcanic Emissions". Remote Sensing 11.11, p. 1302 . DOI: 10.3390 / rs11111302.

Delle Donne, D. and M. Ripepe (2012). "High-frame rate thermal imagery of Strombolian explosions: Implications for explosive and infrasonic source dynamics". Journal of Geophysical Research: Solid Earth 117.B9. Dor: $10.1029 / 2011$ jb008987.

Fee, D. and R. S. Matoza (2013). "An overview of volcano infrasound: From hawaiian to plinian, local to global". Journal of Volcanology and Geothermal Research 249, pp. 123-139. Dor: 10.1016 / j . jvolgeores.2012.09.002.

Fischer, T. P., K. Roggensack, and P. R. Kyle (2002). "Open and almost shut case for explosive eruptions: Vent processes determined by $\mathrm{SO} 2$ emission rates at Karymsky volcano, Kamchatka". Geology 30.12, p. 1059. Dor: $10.1130 / 0091-7613$ (2002) 030<1059: oaascf $>2.0$.co;2.

Galle, B., M. Johansson, C. Rivera, Y. Zhang, M. Kihlman, C. Kern, T. Lehmann, U. Platt, S. Arellano, and S. Hidalgo (2010). "Network for Observation of Volcanic and Atmospheric Change (NOVAC) - A global network for volcanic gas monitoring: Network layout and instrument description". Journal of Geophysical Research 115.D5. Dor: 10 . 1029 / 2009 jd011823.

Galle, B., C. Oppenheimer, A. Geyer, A. J. McGonigle, M. Edmonds, and L. Horrocks (2003). "A miniaturised ultraviolet spectrometer for remote sensing of SO2 fluxes: a new tool for volcano surveillance". Journal of Volcanology and Geothermal Research 119.14, pp. 241-254. DOI: 10 . 1016 / s0377 - 0273(02 ) 00356-6.

Gliß, J., K. Stebel, A. Kylling, and A. Sudbø (2018). "Improved optical flow velocity analysis in $\mathrm{SO}_{2}$ camera images of volcanic plumes - implications for emission-rate retrievals investigated at Mt Etna, Italy and Guallatiri, Chile". Atmospheric Measurement Techniques 11.2, pp. 781-801. Dor: 10.5194 / amt 11-781-2018.

Holland, A. P., I. M. Watson, J. C. Phillips, L. Caricchi, and M. P. Dalton (2011). "Degassing processes during lava dome growth: Insights from Santiaguito lava dome, Guatemala". Journal of Volcanology and Geothermal Research 202.1-2, pp. 153-166. DOI: 10 . 1016 / j . jvolgeores.2011.02.004.

Johnson, J. B. (2004). "Volcanic eruptions observed with infrasound". Geophysical Research Letters 31.14. Dor: 10. 1029/2004gl020020.

Johnson, J. B., J. M. Lees, and E. I. Gordeev (1998). "Degassing explosions at Karymsky Volcano, Kamchatka". Geophysical Research Letters 25.21, pp. 39994002. Dor: $10.1029 / 1998 g 1900102$. 
Kantzas, E. P., A. McGonigle, G. Tamburello, A. Aiuppa, and R. G. Bryant (2010). "Protocols for UV camera volcanic SO2 measurements". Journal of Volcanology and Geothermal Research 194.1-3, pp. 55-60. Dor: 10. 1016/j . jvolgeores.2010.05.003.

Kern, C., S. Arellano, Z. Chacon, D. Norgard, S. Hidalgo, and C. Rivera (2018). 6th NOVAC Workshop report. Tech. rep. Arequipa and Chivay, Peru.

Kern, C., T. Deutschmann, L. Vogel, M. Wöhrbach, T. Wagner, and U. Platt (2010). "Radiative transfer corrections for accurate spectroscopic measurements of volcanic gas emissions". Bulletin of Volcanology 72.2, pp. 233-247. Dor: 10.1007/s00445-009-0313-7.

Kern, C., P. Masias, F. Apaza, K. A. Reath, and U. Platt (2017). "Remote measurement of high preeruptive water vapor emissions at Sabancaya volcano by passive differential optical absorption spectroscopy". Journal of Geophysical Research: Solid Earth 122.5, pp. 3540-3564. DoI: 10. 1002/2017 jb014020.

Kern, C., C. Werner, T. Elias, A. J. Sutton, and P. Lübcke (2013). "Applying UV cameras for SO2 detection to distant or optically thick volcanic plumes". Journal of Volcanology and Geothermal Research 262, pp. 80-89. Dor: 10.1016/ j . jvolgeores.2013.06.009.

Klein, A., P. Lübcke, N. Bobrowski, J. Kuhn, and U. Platt (2017). "Plume propagation direction determination with $\mathrm{SO}_{2}$ cameras". Atmospheric Measurement Techniques 10.3, pp. 979-987. Dor: 10.5194 / amt - 10 979-2017.

Lees, J. M. and M. Ruiz (2008). "Non-linear explosion tremor at Sangay, Volcano, Ecuador". Journal of Volcanology and Geothermal Research 176.1, pp. 170-178. Dor: $10.1016 / \mathrm{j}$. jvolgeores.2007.08.012.

Lübcke, P., N. Bobrowski, S. Illing, C. Kern, J. M. A. Nieves, L. Vogel, J. Zielcke, H. D. Granados, and U. Platt (2013). "On the absolute calibration of $\mathrm{SO}_{2}$ cameras". Atmospheric Measurement Techniques 6.3, pp. 677-696. Dor: 10.5194/amt-6-677-2013.

Lübcke, P., J. Lampel, S. Arellano, N. Bobrowski, F. Dinger, B. Galle, G. Garzón, S. Hidalgo, Z. C. Ortiz, L. Vogel, S. Warnach, and U. Platt (2016). "Retrieval of absolute $\mathrm{SO}_{2}$ column amounts from scattered-light spectra: implications for the evaluation of data from automated DOAS networks". Atmospheric Measurement Techniques 9.12, pp. 5677-5698. Dor: 10.5194/ amt-9-5677-2016.

Manrique, N., I. Lazarte, M. Rivera, K. Cueva, S. Japura, and R. Aguilar (2018). "Actividad del volcán Sabancaya (Perú) 2016-2017: observaciones petrográficas y geoquímicas de los depósitos de tefras del 2017". Hazard and Risk Mapping: The Arequipa - El Misti Case Study and Other Threatened Cities. Ed. by J. Thouret. Presses universitaires Blaise Pascal, Clermont-Ferrand, France, pp. 117-122.

Masías Alvarez, P. and F. Apaza Choquehuayta (2018). "Implementación de la Red de monitoreo de $\mathrm{SO}_{2}$
(DOAS) en los volcanes activos del Perú (Ubinas y Sabancaya)". Libro de resúmenes: VIII Foro Internacional los Volcanes y su Impacto, Arequipa, 26 y 27 de abril del 2018.

McGonigle, A. J. S., A. Aiuppa, M. Ripepe, E. P. Kantzas, and G. Tamburello (2009). "Spectroscopic capture of $1 \mathrm{~Hz}$ volcanic SO2fluxes and integration with volcano geophysical data". Geophysical Research Letters 36.21. DOI: $10.1029 / 2009 \mathrm{gl} 040494$.

McGonigle, A. J. S., T. D. Pering, T. C. Wilkes, G. Tamburello, R. D'Aleo, M. Bitetto, A. Aiuppa, and J. R. Willmott (2017). "Ultraviolet Imaging of Volcanic Plumes: A New Paradigm in Volcanology". Geosciences 7.3, p. 68. DOI: $10.3390 /$ geosciences7030068.

Mori, T., T. Mori, K. Kazahaya, M. Ohwada, J. Hirabayashi, and S. Yoshikawa (2006). "Effect of UV scattering on SO2emission rate measurements". Geophysical Research Letters 33.17. Dor: 10 . 1029 / $2006 \mathrm{gl} 026285$.

Moussallam, Y., G. Tamburello, N. Peters, F. Apaza, C. I. Schipper, A. Curtis, A. Aiuppa, P. Masias, M. Boichu, S. Bauduin, T. Barnie, P. Bani, G. Giudice, and M. Moussallam (2017). "Volcanic gas emissions and degassing dynamics at Ubinas and Sabancaya volcanoes: implications for the volatile budget of the central volcanic zone". Journal of Volcanology and Geothermal Research 343, pp. 181-191. Dor: 10.1016/ j. jvolgeores.2017.06.027.

Nadeau, P. A., J. L. Palma, and G. P. Waite (2011). "Linking volcanic tremor, degassing, and eruption dynamics via SO2imaging". Geophysical Research Letters 38.1. DoI: $10.1029 / 2010 \mathrm{gl} 045820$.

OVI-INGEMMET \& IGP (2018). Reporte semenal de monitoreo de la actividad del volcan Sabancana - semana del 23 al 29 de abril de 2018 (No. RSSAB-17-2018). Tech. rep.

Peters, N., A. Hoffmann, T. Barnie, M. Herzog, and C. Oppenheimer (2015). "Use of motion estimation algorithms for improved flux measurements using SO 2 cameras". Journal of Volcanology and Geothermal Research 300, pp. 58-69. Dor: 10.1016/ j . jvolgeores . 2014.08 .031$.

Peters, N. and C. Oppenheimer (2018). "Plumetrack: Flux calculation software for UV cameras". Computers E Geosciences 118, pp. 86-90. Dor: $10.1016 / \mathrm{j}$. cageo.2018.05.014.

Prata, A. J. (2013). "Measuring $\mathrm{SO}_{2}$ ship emissions with an ultra-violet imaging camera". Atmospheric Measurement Techniques Discussions 6.6, pp. 9467-9511. DOI: 10.5194/ amtd-6-9467-2013.

Ramos Palomino, D., P. Masías Alvarez, F. Apaza Choquehuayta, I. Lazarte Zerpa, E. Taipe Maquerhua, R. Miranda Cruz, M. Ortega Gonzáles, R. Anccasi Figueroa, B. Callata Pacsi, J. Calderón, and M. Rivera Porras (2016). Los inicios de la actividad eruptiva 2016 del volcán Sabancaya. Tech. rep. 
Samaniego, P., M. Rivera, J. Mariño, H. Guillou, C. Liorzou, S. Zerathe, R. Delgado, P. Valderrama, and V. Scao (2016). "The eruptive chronology of the Ampato-Sabancaya volcanic complex (Southern Peru)". Journal of Volcanology and Geothermal Research 323, pp. 110-128. Dor: 10.1016/ j . jvolgeores . 2016.04. 038.

Smekens, J.-F., M. R. Burton, and A. B. Clarke (2015a). "Validation of the $\mathrm{SO} 2$ camera for high temporal and spatial resolution monitoring of $\mathrm{SO} 2$ emissions". Journal of Volcanology and Geothermal Research 300, pp. 37-47. Dor: 10.1016 / j . jvolgeores . 2014 . 10 . 014.

Smekens, J.-F., A. B. Clarke, M. R. Burton, A. Harijoko, and H. E. Wibowo (2015b). "SO 2 emissions at Semeru volcano, Indonesia: Characterization and quan- tification of persistent and periodic explosive activity". Journal of Volcanology and Geothermal Research 300, pp. 121-128. Dor: $10.1016 / \mathrm{j}$. jvolgeores . 2015.01.006.

Wilkes, T., A. McGonigle, T. Pering, A. Taggart, B. White, R. Bryant, and J. Willmott (2016). "Ultraviolet Imaging with Low Cost Smartphone Sensors: Development and Application of a Raspberry Pi-Based UV Camera". Sensors 16.10, p. 1649. Dor: $10.3390 /$ s16101649.

Wilkes, T., T. Pering, A. McGonigle, G. Tamburello, and J. Willmott (2017). "A Low-Cost Smartphone SensorBased UV Camera for Volcanic SO2 Emission Measurements". Remote Sensing 9.1, p. 27. DoI: 10.3390/ rs9010027. 